\title{
Entrevista com o professor Gilles Dussault: Desafios dos sistemas de saúde contemporâneos, por Eleonor Minho Conill, Ligia Giovanella e José-Manuel Freire
}

\author{
Interview with Professor Gilles Dussault: \\ The challenges facing contemporary health systems, \\ by Eleonor Minho Conill, Ligia Giovanella and José-Manuel Freire
}

Gilles Dussault é professor catedrático convidado da Unidade de Saúde Internacional e Bioestatística do Instituto de Higiene e Medicina Tropical (IHMT), Lisboa, Portugal, desde agosto de 2006. Anteriormente exerceu funções de Senior Health Specialist do Instituto do Banco Mundial, em Washington, D.C. Foi responsável pelas atividades regionais do Programa "Reforma do Sector da Saúde e Financiamento Sustentável”, em diversos países de língua oficial francesa, portuguesa e espanhola, nos quais o Banco Mundial se encontrava em atividade. Seu trabalho concentrou-se no financiamento do setor saúde e em políticas de recursos humanos da saúde. Entre 1985 e 2000, assumiu funções como professor e diretor do Departamento de Administração da Saúde da Universidade de Montreal. Tem lecionado em diversos países. No Brasil, foi professor visitante na Escola Nacional de Saúde Pública Sergio Arouca (1991-92). Suas publicações concentram-se em torno de tópicos relacionados com a regulação e a gestão dos recursos humanos da saúde. Realizou diversos projetos de consultoria para agências de cooperação multilaterais e bilaterais e colabora com comitês editoriais e grupos de trabalho internacionais como a Organização Mundial da Saúde e o Observatório Europeu dos Sistemas e Politicas de Saúde.
Conill, Giovanella, Freire O senhor teve a oportunidade de vivenciar diversos contextos de organização de sistemas de saúde por ter morado, estudado ou trabalhado na América do Norte (Québec e Estados Unidos), na Inglaterra, Austrália, América Latina (Brasil) e, atualmente, por estar em Portugal. Sabemos que também trabalhou com o continente africano durante seu período profissional no Banco Mundial. Quais são os aspectos essenciais que devem ser levados em conta nas reformas visando melhorar a qualidade dos serviços de saúde? Existem pontos comuns, apesar de esses contextos serem tão diversos? Quais especificidades são importantes e devem ser consideradas?

Dussault Apesar de cada país e, em muitos casos, cada região (como em Espanha, Itália), província (como em Canadá) ou estado (como a Alemanha) nos países federais ter suas especificidades, há princípios que se aplicam a todos. Uma lista não exaustiva inclui: (1) a adoção de objetivos claros e específicos em termos de qualidade nas suas dimensões técnicas (respeito pelas normas profissionais) e de serviço (aspectos não clínicos dos serviços, a chamada responsiveness); (2) um verdadeiro compromisso político ao mais alto nível que apoie esses objetivos; (3) a mobilização da capacidade para atingir os objetivos. Esta capacidade deve existir em três níveis: no nível da força de trabalho (que produz serviços que devem compreender competências técnicas adequadas e motivação para 
prestar serviços de alta qualidade); no nível das organizações prestadoras (para criar um ambiente e modalidades de trabalho favoráveis ao bom desempenho, por exemplo, através do trabalho em equipe, acesso a ferramentas funcionais, e processos de gestão que facilitem o trabalho profissional); e no nível institucional, ou seja, do quadro regulador no sector da saúde, através de mecanismos adaptados de financiamento das organizações e de pagamento dos prestadores e de regulação da qualidade, por exemplo, pelos conselhos profissionais reforçados. Neste nível, devem ser definidos sistemas de incentivos alinhados com os resultados esperados. É obvio que a produção de serviços de qualidade exige recursos financeiros suficientes, mas os entraves à melhoria da qualidade são mais os de natureza organizacional e cultural que influenciam os comportamentos dos prestadores.

Conill, Giovanella, Freire Países de tradição político-administrativa napoleônica (França, Espanha, Itália, Portugal, América Latina, entre outros) parecem ter mais dificuldades que os de tradição anglo-saxã para modernizar seus serviços públicos, incluindo os sistemas de saúde. Considerando essa ampla experiência em contextos políticos, administrativos e culturais distintos, qual é sua percepção acerca das iniciativas de muitos países da América Latina de reformar seus esquemas de governo e gestão dos serviços públicos para melhorar sua qualidade e eficiência? Quais seriam suas observações para contribuir na direção de uma nova cultura nos serviços públicos desses países?

Dussault A grande diferença entre os países de tradição anglo-saxônica e os de cultura latina é o grau de profissionalização e correspondente despolitização da gestão dos serviços de saúde e, em geral, dos serviços públicos.

Sistemas meritocráticos de seleção dos gestores (inclusivamente os de topo) favorecem uma gestão mais racional, baseada em regras administrativas, e não em critérios políticos. Há uma tradição mais antiga de formação em gestão em saúde e de nomeação para postos de direção em que esta resulta das competências e experiências que correspondem às exigências específicas da função. Também a seleção dos gestores em nível das organizações é feita de modo autônomo. O Ministério da Saúde ou o Sistema Nacional de Saúde não intervêm, uma vez as regras gerais sejam respeitadas. Há, também, menos rotação do pessoal. Por exemplo, a chegada de um novo ministro, ou de um novo diretor de hospital, não é automaticamente acompanhada por movimentos de pessoal dirigente, o que favorece a continuidade na gestão e na implementação das políticas.

Além de recrutar gestores competentes e dedicados, outras estratégias são importantes para melhorar a efetividade e a eficiência dos serviços públicos. Incluo a disponibilidade de sistemas de informação que permitem monitorizar em tempo real as principais dimensões do desempenho dos serviços públicos, tal como tempos de espera, níveis de satisfação dos utentes, rotatividade e absentismo do pessoal ou variações na produção.

Em muitos países, os sistemas que existem servem as necessidades da administração central, sem atender às dos que dirigem os serviços. Nos países de tradição anglo-saxônica tal também acontece, mas é comum, nas organizações prestadoras, existir um scorecard com indicadores que facilitam o monitoramento contínuo da produção, dos custos e da qualidade. Desta forma, os dirigentes podem reagir rapidamente quando se apercebem de possíveis problemas.

A qualidade dos serviços depende diretamente do comportamento dos profissionais e outros trabalhadores que contribuem para sua produção. Por essa razão, a educação e a formação ao longo da vida profissional jogam um papel decisivo no desenvolvimento de competências e atitudes que favoreçam a prestação de serviços.

A passagem da formação didática tradicional à formação baseada na resolução de problemas tem ajudado muito na sensibilização dos profissionais para as dimensões de qualidade para além da clínica e para a necessidade da melhoria da eficiência. Os alunos expostos desde o principio da formação a problemas complexos tendem a entender melhor que serviços de qualidade são serviços tecnicamente bem prestados, mas também serviços que respondem a outros critérios importantes para o utente, como a cortesia, a boa comunicação, a compreensão pelo contexto de vida da pessoa, a informação adequada etc. A criação de uma cultura profissional que internaliza a avaliação como ferramenta de melhoria da qualidade, e não somente como mecanismo de controlo, é fundamental para favorecer atitudes criticas e comportamentos adaptados a uma busca contínua pela qualidade.

Uma fraqueza observada em quase todos os países é a negligência na formação do pessoal de apoio, desde porteiros a auxiliares, passando pelo pessoal de limpeza, que também necessitam de adquirir competências básicas que favoreçam o trabalho de qualidade.

Finalmente, o desenvolvimento da investigação avaliativa pode ser um bom investimento para a melhoria contínua da qualidade. Conhecimen- 
tos derivados da investigação rigorosa podem informar melhor a tomada de decisão tanto em nível clínico como administrativo. A tradição anglo-saxônica é mais forte neste nível como se depreende da literatura cientifica, mas os países de América Latina, como o Brasil ou o México, estão a realizar grandes progressos. Uma força de países como Canadá ou Inglaterra é a disponibilidade de organizações que promovem e facilitam a transferência dos conhecimentos do mundo acadêmico para o mundo da gestão dos serviços ${ }^{1,2}$.

Conill, Giovanella, Freire $\mathrm{Na}$ maior parte dos países periféricos, a universalidade não se concretizou. A proteção social é segmentada e os sistemas de saúde são ainda fragmentados com diversas configurações de mix públicos privados: no financiamento, na regulação, na prestação de serviços, e no emprego em saúde. As relações público-privado são um tema, portanto, crucial nas reformas que objetivam a universalidade com equidade nos nossos países. Em sua opinião, quais as regras cruciais de regulação das relações público-privado para avançar na construção de sistemas universais, solidários e equitativos? O financiamento público é suficiente para garantia de acesso equitativo ou é necessário que a prestação de serviços também seja pública e os profissionais de saúde tenham dedicação ao serviço público? Como evitar redes de serviços segmentadas por estratos populacionais (atenção à saúde de primeira e segunda?)

Dussault Vou responder em dois tempos. Num primeiro momento, apresento o meu raciocínio sobre como dar uma resposta racional aos desafios da universalidade, e num segundo, vou tentar explicar por que motivo tantos países não conseguem concretizar a promessa da universalidade e o que a relação público-privado tem a ver com isso.

Parto da premissa que a universalidade, uma escolha de valor, implica que todos possam receber serviços de qualidade que correspondam às suas necessidades, ou seja, que haja equidade de acesso aos serviços de saúde. Países que se comprometam com este objetivo devem responder a perguntas complexas: o que são necessidades em saúde? Quem as define? Que serviços cobrir? Quem vai os prestar e como? Como os financiar? Quem paga e como?

Não há definição consensual do que são necessidades; depende das dimensões da saúde consideradas e de quem vai definir o que é necessário. O ponto de vista do clínico, o do cidadão ou o do pagador nem sempre coincidem. Um processo de planejamento, baseado numa análise si- tuacional que documente o perfil epidemiológico da população e que toma em conta as expectativas dos cidadãos, é uma ferramenta indispensável. É responsabilidade do Estado conduzir este processo de planejamento, pois a lógica do sector privado é responder à procura de serviços e não às necessidades.

Em relação aos serviços a cobrir, o papel do Estado é garantir a cobertura, diretamente ou por delegação ou contratação, de serviços que correspondem a "bens públicos" e para os quais não há alternativa. São os bens e serviços que têm externalidades positivas importantes, como a vacinação, a proteção do meio ambiente ou a promoção da saúde. São também serviços para responder a problemas raros que não têm interesse econômico para o privado ou problemas complexos que implicam despesas que poucos cidadãos podem sustentar. O privado pode participar na prestação de qualquer serviço, mas sempre aderindo a objetivos públicos e respeitando o princípio de que serviços cuja eficácia não está demonstrada ou não é, pelo menos, plausível, não devem ser cobertos. Hoje em dia, a literatura científica é suficiente para eliminar procedimentos e serviços ineficazes ou mesmo danosos, de maneira que não há justificativa para os continuar a cobrir.

Nas modalidades de prestação, a organização dos serviços deve ser planejada, também, em termos da divisão de tarefas e das ligações entre as componentes do sistema de serviços. Mas as organizações prestadoras devem ter a autonomia de decidir como o realizar mandato e prestar contas, o que supõe a existência de uma capacidade de gestão. Dada a sua responsabilidade em garantir que todos possam receber serviços de qualidade correspondendo à suas necessidades, o papel principal do Estado será planejar, regular, monitorizar, e não necessariamente prestar os serviços.

Quanto devemos gastar em saúde? Não há resposta; depende das necessidades, dos objetivos, e de como vamos gastar. Sem dados e informação de qualidade sobre quanto gastamos, de onde vem e para onde vai o dinheiro, quais são os benefícios, e sem objetivos de saúde e de serviços a oferecer, é difícil responder a essa pergunta e resistir aos grupos que pressionam para gastar mais nos serviços do seu interesse. Para pagar os serviços há varias opções: o utente paga, o utente compra um seguro que paga uma parte mais ou menos completa dos custos, o Estado paga tudo ou uma parte, a partir de impostos específicos ou do tesouro geral, ou um misto dessas opções. Não são todas compatíveis com o objetivo da 
equidade de acesso: cada vez que o utente tem de pagar diretamente ou através de um seguro particular, existe um obstáculo econômico potencial ao acesso. É o caso das taxas moderadoras, uma medida intrinsecamente regressiva, que pode limitar o acesso dos mais pobres, mesmo quando existem isenções. Essas taxas são impostas para "disciplinar" a procura desnecessária de serviços, mas não há evidência nesse sentido: não é claro o que é procura desnecessária e de qualquer maneira, a maioria dos serviços de custo elevado apenas são acessíveis só com a prescrição (autorização) de um profissional. A única fonte de financiamento que pode garantir a equidade de acesso é o orçamento geral e é o modo de financiar mais barato em termos de custos de transação, em comparação ao financiamento por várias fontes (caixas de segurança social, seguros privados). Quanto às modalidades de financiamento e de pagamento (orçamento histórico, por linha, global, per capita, salário, pagamento ligado ao desempenho), é importante ver o que vai favorecer mais a equidade. Por exemplo, o que favorece mais a produtividade ou a atração e retenção de profissionais em zonas carentes?

Não conheço um só país que consiga garantir a equidade de acesso. Nos países ricos, há serviços, como os cuidados dentários, alguns medicamentos, ou as consultas de psicologia, que ficam a custo do utente por não serem incluídos na categoria de serviços necessários. É o caso no Canadá. Noutros países, a gratuidade não está garantida; o sistema público não cobre a totalidade dos custos, como na França ou em Portugal (onde a Constituição diz que os serviços serão "tendencialmente" gratuitos! A meu ver, ou são gratuitos, ou não são). O resultado é que quando consideramos a despesa total, em países que cobrem todos os cidadãos, ou mesmo os residentes, o componente de financiamento público varia entre $85 \%$ (Dinamarca, Noruega) e 70\% (Canadá, Portugal); em comparação, em Brasil, é de 42\%; de 45\% no México e de $51 \%$ na Argentina. A parte privada do financiamento inclui os pagamentos diretos, o pagamento de seguros e as contribuições de organizações caritativas.

Em resumo, a universalidade é melhor garantida quando há um compromisso autêntico e contínuo em nível do governo, quando há um financiador único, quando a organização e a prestação dos serviços e a alocação dos recursos estão alinhados com as necessidades, quando há uma gestão competente, e quando há sistemas de compensação (remuneração, incentivos financeiros e outros) que favorecem o tipo de desempenho desejado.
Por que alguns países ainda não conseguem garantir a universalidade, apesar de a prometer a seus cidadãos? As razões são de vários tipos: algumas são de natureza política. Os governos não sempre consideram a saúde como prioridade, porque outros interesses dominam ou resistam às reformas que a universalidade exige. Quando existe um sector privado forte, o Estado tem muito mais dificuldade em exercer seu papel planejador e regulador. Sistemas bem estabelecidos como os do Canadá, da Inglaterra, ou dos países escandinavos desenvolveram-se a uma época quando havia poucos interesses privados lucrativos, como seguros ou entidades prestadoras, a ocupar o mercado. Os grupos profissionais, quando não são associados aos esforços a favor de uma maior equidade de acesso, podem constituir uma oposição forte.

Os países menos ricos não têm condições para financiar os serviços de saúde a partir dos impostos gerais, basicamente porque não tem capacidade (ou vontade política) para captar os impostos que deveriam arrecadar. Alguns ainda dependem da ajuda externa para sustentar seus serviços de saúde. Outros têm recursos, mas por preferência políticas, as utilizam em obras "visíveis". Esses países têm pouca tradição e uma capacidade limitada de planejamento em geral, e em saúde em particular, e há pouca continuidade na implementação das reformas. Mas não é sempre assim, como o demonstra os esforços do Brasil no sector da saúde da família, que pode servir de exemplo de boa prática a outros países da região. Além disso, a voz do cidadão está fraca. Os que têm capacidade de influenciar as decisões políticas tendem a utilizar serviços privados, incluindo fora do país, e não têm grande interesse em promover e defender a ideia da universalidade ou de serviços públicos fortes. É assim que a "fragmentação" e a saúde a duas velocidades vai provavelmente continuar a existir na America Latina, até o dia em que as maiores autoridades e lideranças considerem-se como utentes dos serviços públicos e solidários de todos os outros cidadãos do país.

\section{Referências}

1. Canadian Health Services Research Foundation. [site na internet]. 2011 [acessado 2011 abr 14]. Disponível em: http://www.chsrf.ca

2. Health Foundation. [site na Internet]. 2011 [acessado 2011 abr 14]. Disponível em: http://www.health. org.uk/ 